\title{
COMMENTARY
}

\section{First evidence of a pro-inflammatory response to severe infection with influenza virus $\mathrm{H} 1 \mathrm{~N} 1$}

\author{
Isabel Fernández de Castro, María Guzmán-Fulgencio, Mónica García-Álvarez and Salvador Resino*
}

See related research by Bermejo-Martin et al., http://ccforum.com/content/13/6/R201

\begin{abstract}
The great majority of infections caused by the pandemic variant of the influenza virus (nvH1N1) are self-limited, but a small percentage of patients develop severe symptoms requiring hospitalization. Bermejo-Martin and colleagues have presented a pilot study describing the differences in the early immune response for patients both mildly and severely infected with nvH1N1. Patients who develop severe symptoms after nvH1N1 infection showed Th1 and Th17'hypercytokinemia', compared to mildly infected patients and healthy controls. The mediators involved with the Th1 and Th17 profiles are known to be involved in antiviral, pro-inflammatory and autoimmune responses. This is the first work reporting the association of a pro-inflamatory immune response with a severe pandemic infection, although it is likely that more studies are needed to understand the detrimental or beneficial roles these cytokines play in the evolution of mild and severe nvH1N1 infection.
\end{abstract}

In a recent article for Critical Care, Bermejo-Martin and colleagues [1] describe Th1 and Th17 hypercytokinemia as an early signature host response to severe infection by the pandemic variant of the influenza virus (nvH1N1). The nvH1N1 infection is usually self-limiting in nature, but some patients develop severe symptoms requiring hospitalization [2]. The host immune response may play an important role in poor outcomes after infection. The human host immune response to nvH1N1 infection is unknown at this time and studies on its contribution to disease pathogenesis are desperately needed to improve prevention and treatment strategies.

*Correspondence: sresino@isciii.es

Centro Nacional de Microbiología, Instituto de Salud Carlos III (Campus

Majadahonda); Carretera Majadahonda-Pozuelo, Km 2.2; 28220 Majadahonda (Madrid), Spain
By analyzing 29 cytokines and chemokines and the hemagglutination inhibition activity, Bermejo-Martin and colleagues [1] assessed the early host innate and adaptive immune responses in patients both mildly and severely infected with nvH1N1. While infection with nvH1N1 induces a typical innate response in both mild and severe cases, severe infections with respiratory involvement are characterized by an early secretion of Th17 and Th1 cytokines. Thus, hospitalized patients tend to show high systemic levels of mediators that stimulate Th17 (IL-8, IL-9, IL-17, IL-6) and Th1 responses (IFN- $\gamma$, TNF- $\alpha$, IL-15, IL-12p70) [1]. Based on this finding, this study was able to highlight similarities between the cytokine response to severe $\mathrm{H} 1 \mathrm{~N} 1$ infection and the pathogenesis of asthma and some autoimmune diseases.

The Th1 response is primarily involved with host immune defense against intracellular pathogens by activating cellular immunity. This response is effective in eradicating infectious agents such as viruses [3]. Indeed, Th1 cells produce IFN- $\gamma$ and cytokines that are involved in monocyte/macrophage-mediated inflammatory responses [4]. When the Th1 response is exhaustively prolonged, it may result in host damage. Moreover, other authors have reported that Th1-dominated responses may be implicated in the pathogenesis of autoimmune disorders and chronic inflammatory diseases [5]. BermejoMartin and colleagues [1] found IL-15, IL-12p70, and IL-6 to be particularly elevated following severe nvH1N1 infection. These three cytokines are known to mediate both antiviral and pro-inflammatory responses. The authors [1] also found a significant inverse relationship of IL- 6 and IL-8 with the pressure of oxygen in arterial blood in severely infected patients. Interestingly, previous studies had already reported high levels of specific proinflammatory cytokines and chemokines in severe SARS coronavirus, H5N1 and respiratory syncytial virus infections [6-11].

Th17 cells are required for host defense against intracellular pathogens [12]. Th17 promotes inflammation by inducing various pro-inflammatory cytokines and chemokines, recruiting neutrophils, enhancing antibody production, and activating T cells [12]. Th17 cells secrete 
IL-17, IL-17F, and IL-22, thereby inducing a massive tissue reaction. Also, these cells secrete IL-21 to communicate with the cells of the immune system [13]. However, uncontrolled production of these cytokines induces tissue damage in infected tissues [12]. In addition, Th17 cells have a well-known role in clearing pathogens during infections and inducing tissue inflammation in autoimmune disease [13]. Interestingly, the key role of IL-17 and its receptor in the immunopathology of influenza infection in a mouse model has just recently been reported [14].

Taken together, these findings show that severe pandemic H1N1 infection is characterized by early elevation of key immune pro-inflammatory mediators participating in both Th1 and Th17 inflammatory responses. This pro-inflammatory response may be the cause of the severe respiratory symptoms caused by nvH1N1 infection. However, the authors also provide an alternative version of the story: Th1 and Th17 cytokines may reflect a vigorous antiviral host response necessary for viral clearance. This article [1] is the first that describes an association between severe influenza infection and a Th17 response in humans. The researchers correctly bring up the fact that a better understanding of the immune response to the new H1N1 virus could contribute to the design of more effective therapies. Similarly, the results of this study reinforce the importance of early treatment with antivirals in those patients with high risk factors, such as pregnancy, asthma, and obesity, among others, to avoid triggering unwanted inflammatory phenomena, which could explain the appearance of pneumonia in these patients. The results of this work also support the study of drugs that modulate the immune response in the treatment of this disease [15]. Moreover, the study of genetic polymorphisms of relevant genes involved in the development of Th1 and Th17 immune responses in severely infected patients could be of interest, since these polymorphisms could strongly influence gene expression.

Further studies would help to understand the harmful or beneficial roles that these cytokines play in the evolution of mild and severe nvH1N1 infection. But this report confirms that Th1 and Th17 responses are distinctive hallmarks of severe respiratory compromise following nvH1N1 infection.

\section{Abbreviations}

IFN = interferon gamma; $I \mathrm{~L}=$ interleukin; $\mathrm{nvH} 1 \mathrm{~N} 1$ = new variant of $\mathrm{H} 1 \mathrm{~N} 1$

influenza virus; TNF = tumor necrosis factor

\section{Acknowledgements}

This work was supported by grants from Instituto de Salud Carlos III (PI08/0738; UIPY 1467/07) to SR. MG-F is supported by a grant of Instituto de Salud Carlos III (CM09/00031). MG-A is supported by a grant of Instituto de Salud Carlos III (CM08/00101).
Competing interests

The authors declare that they have no competing interests.

Published: 11 February 2010

\section{References}

1. Bermejo-Martin JF, Ortiz de Lejarazu R, Pumarola T, Rello J, Almansa R, Ramírez P, Martin-Loeches I, Varillas D, Gallegos MC, Serón C, Micheloud D, Gomez JM, Tenorio-Abreu A, Ramos MJ, Molina ML, Huidobro S, Sanchez E, Gordón M, Fernández V, Del Castillo A, Marcos MA, Villanueva B, López CJ, RodríguezDomínquez M, Galan JC, Cantón R, Lietor A, Rojo S, Eiros JM, Hinojosa C, et al.: Th1 and Th17 hypercytokinemia as early host response signature in severe pandemic influenza. Crit Care 2009, 13:R201.

2. Nicoll A, Coulombier D: Europe's initial experience with pandemic (H1N1) 2009 - mitigation and delaying policies and practices. Eur Surveill 2009, 14.

3. Romagnani S: Th1/Th2 cells. Inflamm Bowel Dis 1999, 5:285-294.

4. Muraille E, Leo O: Revisiting the Th1/Th2 paradigm. Scand J Immunol 1998, 47:1-9.

5. Romagnani S: Th1 and Th2 in human diseases. Clin Immunol Immunopathol 1996, 80:225-235.

6. Bermejo-Martin JF, Garcia-Arevalo MC, Alonso A, De Lejarazu RO, Pino M, Resino S, Tenorio A, Bernardo D, Leon AJ, Garrote JA, Ardura J, Dominguez-Gil M, Eiros JM, Blanco-Quiros A, Munoz-Fernandez MA, Kelvin DJ, Arranz E: Persistence of proinflammatory response after severe respiratory syncytial virus disease in children. J Allergy Clin Immunol 2007, 119:1547-1550.

7. Cameron CM, Cameron MJ, Bermejo-Martin JF, Ran L, Xu L, Turner PV, Ran R, Danesh A, Fang Y, Chan PK, Mytle N, Sullivan TJ, Collins TL, Johnson MG, Medina JC, Rowe T, Kelvin DJ: Gene expression analysis of host innate immune responses during Lethal H5N1 infection in ferrets. J Viro/ 2008, 82:11308-11317.

8. Cameron MJ, Bermejo-Martin JF, Danesh A, Muller MP, Kelvin DJ: Human immunopathogenesis of severe acute respiratory syndrome (SARS). Virus Res 2008, 133:13-19.

9. Cameron MJ, Ran L, Xu L, Danesh A, Bermejo-Martin JF, Cameron CM, Muller MP, Gold WL, Richardson SE, Poutanen SM, Willey BM, DeVries ME, Fang Y, Seneviratne C, Bosinger SE, Persad D, Wilkinson P, Greller LD, Somogyi R, Humar A, Keshavjee S, Louie M, Loeb MB, Brunton J, McGeer AJ; Canadian SARS Research Network, Kelvin DJ: Interferon-mediated immunopathological events are associated with atypical innate and adaptive immune responses in patients with severe acute respiratory syndrome. J Viro/ 2007, 81:8692-8706.

10. de Jong MD, Simmons CP, Thanh TT, Hien VM, Smith GJ, Chau TN, Hoang DM, Chau NV, Khanh TH, Dong VC, Qui PT, Cam BV, Ha do Q, Guan Y, Peiris JS, Chinh NT, Hien TT, Farrar J: Fatal outcome of human influenza A (H5N1) is associated with high viral load and hypercytokinemia. Nat Medods 2006, 12:1203-1207.

11. Julkunen I, Sareneva T, Pirhonen J, Ronni T, Melen K, Matikainen S: Molecular pathogenesis of influenza A virus infection and virus-induced regulation of cytokine gene expression. Cytokine Growth Factor Rev 2001, 12:171-180.

12. Iwakura Y, Nakae S, Saijo S, Ishigame H: The roles of IL-17A in inflammatory immune responses and host defense against pathogens. Immunol ReV 2008, 226:57-79

13. Korn T, Bettelli E, Oukka M, Kuchroo VK: IL-17 and Th17 cells. Annu Rev Immunol 2009, 27:485-517.

14. Crowe CR, Chen K, Pociask DA, Alcorn JF, Krivich C, Enelow RI, Ross TM, Witztum JL, Kolls JK: Critical role of IL-17RA in immunopathology of influenza infection. J Immuno/ 2009, 183:5301-5310.

15. Bermejo-Martin JF, Kelvin DJ, Eiros JM, Castrodeza J, Ortiz de Lejarazu R: Macrolides for the treatment of severe respiratory illness caused by novel H1N1 swine influenza viral strains. J Infect Dev Ctries 2009, 3:159-161.

doi:10.1186/cc8846

Cite this article as: Fernández de Castro l, et al.: First evidence of a proinflammatory response to severe infection with influenza virus H1N1. Critical Care 2010, 14:115. 